\title{
Transmodernidade e interculturalidade: interpretação a partir da filosofia da libertação*
}

Enrique Dussel**

Resumo: Ao reconhecer uma nova localização das culturas periféricas na história mundial, bem como partindo de uma concepção não monolítica e não substancialista de cultura, este artigo localiza, por um lado, a Europa na história mundial e propõe, por outro, um diálogo intercultural simétrico entre críticos das culturas ditas periféricas. Essas culturas periféricas foram colonizadas, excluídas, desprezadas, negadas e ignoradas pela Modernidade eurocentrada, porém, não foram eliminadas. O desafio que se coloca é o de estabelecer um diálogo transmoderno e simétrico entre essas culturas - tratadas como exterioridades da Modernidade - a fim de responder de outros lugares os desafios da Modernidade e pós-modernidade europeia.

Palavras-chave: transmodernidade, interculturalidade, filosofia da libertação, exterioridade, sistema-mundo.

\section{Centro e periferia cultural:} o problema da libertação

$\mathrm{D}$ esde o final da década de 1960, como fruto do surgimento das ciências sociais críticas latino-americanas (especialmente a "teoria da dependência"), como também da obra Totalidade e infinito de Emmanuel Levinas (1988), e principalmente pelos movimentos populares e estudantis de 1968 (no mundo, notadamente na Argentina e América Latina), se produziu no campo da filosofia, portanto na filosofia da cultura, uma ruptura histórica. O que havia sido considerado como mundo metropolitano e mundo colonial agora era classificado (a partir da terminologia, ainda desenvolvimentista, de Raúl Presbisch - Cepal) como "centro" e "periferia". A isso se deve agregar todo um horizonte categórico proveniente da economia crítica, que exigia a incorporação das classes sociais como atores intersubjetivos a serem integrados a uma definição de cultura. Não se tratava de mera questão terminológica e sim conceitual, que permitia romper com o conceito "substancialista" de cultura, descobrindo suas fraturas internas (dentro de cada cultura) e entre elas (não só como "diálogo" ou "choque intercultural, mas estritamente como dominação e exploração de uma sobre as demais). A assimetria dos atores deveria ser levada em conta em todos os níveis. A etapa "culturalista" tinha acabado. Em 1983, em um capítulo intitulado "Más allá del culturalismo" escrevi:

Para a visão estruturalista do culturalismo, era impossível compreender as situações de mudança de hegemonia, dentro de blocos históricos bem definidos e as formações ideológicas de várias

\author{
* Traduzido do origi- \\ nal "Transmoderni- \\ dad y interculturali- \\ dad: interpretación \\ desde la filosofia \\ de la liberación". \\ Tradução Rodrigo \\ de Freitas Espinoza. \\ Revisão: Joaze Ber- \\ nardino-Costa.
** Professor da Uni- versidad Autónoma Metropolitana-Izta- palapa (UAM-Iz-
Universidad Nacional
Autónoma de Mexico (Unam).<dussamb@ unam.mx>. \\ -México) e da
}


classes e frações [...]. Faltava também, ao culturalismo, as categorias de sociedade política (em última análise, o Estado) e a sociedade civil [...] (Dussel, 1983: 35-36).

A filosofia latino-americana como filosofia da libertação descobria seu condicionamento cultural (pensava-se a partir de uma cultura determinada), mas também articulada (explícita ou implicitamente) a partir dos interesses de classes, grupos, sexo, raça etc. determinados. A location havia sido descoberta e era a primeira questão filosófica a ser tratada. O diálogo intercultural havia perdido sua ingenuidade e passou a ser compreendido como sobredeterminado por todo o período colonial. De fato, em 1974 iniciamos um "diálogo" intercontinental "Sul-Sul" entre os pensadores da África, Ásia e América Latina, cuja primeira reunião foi realizada em Dar-Es-Salaam (Tanzânia) em 1976. Esses encontros deram-nos um novo panorama sobre as grandes culturas da humanidade.

A nova visão sobre a cultura emerge na última reunião realizada na Universidade de El Salvador, em Buenos Aires, já em pleno desenvolvimento da filosofia da libertação, sob o título Cultura imperial, cultura ilustrada e libertação da cultura popular (Dussel, 1997: 121-152). Foi um ataque frontal à posição de Domingo F. Sarmiento (2010), eminente pedagogo argentino, autor da obra Facundo, ou civilização e barbarie. Para Sarmiento, a civilização era a cultura norte-americana; a barbárie, eram os caudilhos federais que lutavam pela autonomia regional contra o Porto de Buenos Aires (cinturão de transmissão do domínio britânico). Era o início da desmistificação de "heróis" nacionais que haviam concebido o modelo neocolonial do país e que mostrava seu esgotamento. Uma cultura "imperial" (a do "centro"), com origem na invasão da América em 1492, enfrentava as culturas "periféricas" na América Latina, África, Ásia e Europa Oriental. Não era um "diálogo" simétrico, mas de dominação, exploração e aniquilação. Além disso, nas culturas "periféricas" existiam elites educadas pelos impérios, como escreveu Sartre (1968) na "Introdução" de Os condenados da Terra, de Frantz Fanon; elites que repetiam como eco o que tinham aprendido em Paris ou Londres; elites ilustradas neocoloniais, leais aos impérios, que se distanciavam de seu próprio "povo" e o utilizavam como refém de sua política dependente. Havia, então, assimetrias de dominação global:

1. uma cultura, a ocidental, metropolitana e eurocêntrica que dominava com a pretensão de aniquilar todas as culturas periféricas;

2. as culturas pós-coloniais (América Latina desde o século XIX e Ásia e África, após a Segunda Guerra Mundial), fragmentadas internamente entre

a. grupos articulados aos impérios, elites "ilustradas", cujo domínio significava dar às costas para a cultura ancestral regional; e 
b. a maioria da população, fiel às suas tradições, defendendo-se (muitas vezes de forma fundamentalista) contra a imposição de uma cultura técnica e economicamente capitalista.

A filosofia da libertação como filosofia crítica cultural precisava gerar uma nova elite cuja "ilustração" iria se articular aos interesses do bloco social dos oprimidos (o que, para Gramsci, era o popolo). Portanto, falava-se em uma "libertação da cultura popular":

Uma delas é a revolução patriótica de libertação nacional, a outra seria a revolução social da libertação das classes oprimidas, e a terceira a revolução cultural. Esta última encontra-se no nível pedagógico, da juventude e da cultura (Dussel, 1997: 137).

Essa cultura periférica oprimida pela cultura imperial deve ser o ponto de partida para o diálogo intercultural. Em 1973, escrevíamos:

A cultura, como cultura popular, longe de ser uma cultura menor, é o centro menos contaminado e radiante da resistência do oprimido contra o opressor [...]. Para criar algo de novo, há de se ter uma palavra nova que irrompa a partir da exterioridade. Esta exterioridade é o próprio povo que, embora oprimido pelo sistema, é o mais distante em relação a este (Dussel, 1973: 147).

O "projeto de libertação cultural" (Dussel, 1973, 147) parte da cultura popular, embora pensado a partir da filosofia da libertação no contexto latino-americano. Já se havia superado o desenvolvimentismo culturalista a sustentar que a partir de uma cultura tradicional se poderia passar a uma cultura secular e pluralista. Mas havia ainda a necessidade de se radicalizar a análise do "popular" (o melhor), que em seu cerne abrigava o populismo e o fundamentalismo (o pior). Será necessário dar um passo além.

\section{A cultura popular:} não é simples populismo

Em artigo que integra o livro Oito ensaios sobre a cultura latino-america e libertação (1997), intitulado "Cultura latinoamericana y filosofia de la liberación (cultura popular revolucionaria mas allá del populismo y del dogmatismo)", tive, uma vez mais, de esclarecer a diferença entre:

a. o "povo" e o "popular";

b. "populismo" (este último tendo faces diferentes: desde "populismo thatcherista" no Reino Unido - sugerido por Ernesto Laclau e estudado 
em Birmingham por Richard Hall - até a figura atual de "fundamentalismo" no mundo muçulmano; "fundamentalismo", que também está presente, por exemplo, nos Estados Unidos, em um cristianismo sectário como o defendido por George W. Bush).

Neste artigo, dividimos o material em quatro seções. No primeiro, reconstruímos as posições desde a década de 1960, mostramos a importância de superar os limites reducionistas (dos revolucionários a-históricos, das histórias liberais, puramente hispanoconservadoras ou indigenistas), reconstruímos a história cultural latino-americana no contexto da história mundial (desde a Ásia, nosso componente ameríndio; a proto-história euro-afro-asiática até a cristandade hispânica; desde a cristandade colonial até a cultura latino-americana dependente, pós-colonial ou neocolonial). Este processo converge para um projeto de "uma cultura popular pós-capitalista":

Quando estávamos nas montanhas, Tomás Borge escrevia sobre camponeses, e ouvi falar ao seu coração puro, limpo, com uma linguagem simples e poética, percebemos quanto talento perdemos [as elites neocoloniais] ao longo dos séculos' (FSLN, 1981: 116).

Isso exigiu um novo ponto de partida para descrever a cultura como tal, tema da segunda seção do capítulo em destaque.

A partir de uma leitura cuidadosa e arqueológica de Marx (desde seus primeiros trabalhos até os da maturidade, escritos entre 1835 e 1882), demostramos que cada cultura é um modo ou um sistema de "tipos de trabalho" (Dussel, 1985; 1988; 1990). Não é por outra razão que "agri-cultura" era estritamente "o trabalho da terra" já que "cultura" tem sua origem etimológica no latim "culto", no sentido da consagração da terra. A poética material (fruto físico do trabalho) e o mítico (criação simbólica) são produções culturais (uma exteriorização objetiva do subjetivo, ou melhor, do intersubjetivo e comunitário). Desta forma, o econômico (sem cair no economicismo) foi resgatado.

1. Para o tema da cultura popular, ver: Bosi (1977), Ardiles (1975), Cabral (1981), Najenson (1979), Warman (1969) e Vidales (1982).
Em uma terceira seção (Dussel, 1997), foram analisados vários momentos, agora fragmentados, da experiência cultural, em uma visão pós-culturalista ou pós-spengleriana. "A cultura burguesa" ( $a$ ) era estudada em relação a "cultura proletária" (b) de forma resumida, a "cultura dos países centrais" era analisada em relação às "culturas dos países periféricos" (na ordem mundial do "sistema-mundo"); a "cultura multinacional ou imperialismo cultural" (c) era descrita em relação à "cultura de massa ou alienada" (d) - globalizada -; "cultura nacional ou populismo cultural" (e) era articulada com a "cultura da elite ilustrada" ( $f$ ) e contrastada com a "cultura popular" ou "a resistência de criação cultural" $(g)^{1}$. 
FIGURA 1

A EXPERIÊNCIA CULTURAL PÓS-CULTURALISTA

\begin{tabular}{|c|c|c|c|c|c|}
\hline \multirow{2}{*}{$\begin{array}{l}\text { (a) Cultura } \\
\text { burguesa }\end{array}$} & Capitalismo & \multicolumn{3}{|c|}{ (c) Cultura multinacional } & \multirow{4}{*}{ 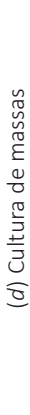 } \\
\hline & $\begin{array}{c}\text { Capitalismo } \\
\text { periférico }\end{array}$ & \multicolumn{2}{|c|}{ (f) Cultura ilustrada } & \multirow{3}{*}{ 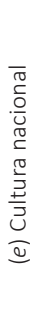 } & \\
\hline $\begin{array}{l}\text { (b) Cultura } \\
\text { proletária }\end{array}$ & $\begin{array}{c}\text { Trabalho } \\
\text { assalariado }\end{array}$ & $\begin{array}{c}\text { Trabalhadores } \\
\text { campesinos }\end{array}$ & $\begin{array}{l}\frac{1}{3} \\
\frac{0}{0} \\
\frac{0}{2}\end{array}$ & & \\
\hline \multicolumn{2}{|c|}{ Guardam a exterioridade* } & $\begin{array}{c}\text { Etnias } \\
\text { Artesãos } \\
\text { Marginalizados } \\
\text { Outros }\end{array}$ & $\begin{array}{l}\frac{\pi}{3} \\
\frac{ \pm}{3} \\
\frac{0}{3}\end{array}$ & & \\
\hline
\end{tabular}

encontram-se "fora" da ordem capitalista, mas no coração do povo.

Evidentemente, esta tipologia cultural e seus critérios categóricos supunham uma longa "luta epistemológica", crítica, própria das novas ciências sociais na América Latina e da filosofia da libertação. Nós já havíamos chegado a estas distinções muito antes, mas agora elas se destacavam definitivamente.

Em 1977, no volume III de Para una ética de la liberación latino-americana, escrevemos:

A cultura imperial² (supostamente universal) não é a mesmo que

2. Em 1984, denominamos "cultura multinacional" em relação às corporações "multinacionais", mas seria mais apropriado chamá-la, em 2003, a "cultura dominante que se globaliza a partir do centro do capitalismo pós-Guerra Fria".

Na década de 1980, com a presença ativa da Frente Sandinista de Libertação Nacional na Nicarágua e muitas outras experiências na América Latina, a cultura criativa foi concebida como "cultura popular revolucionária" (Cardenal, 1980: 163):

A cultura popular latino-americana - escrevíamos no artigo de 1984 - apenas fica clara, decanta, se autentifica no processo de libertação (da libertação econômica do capitalismo, da libertação política da opressão), instaurando um novo modelo democrático, sendo assim libertação cultural, dando um passo criativo na linha da tradição histórico-cultural do povo oprimido e agora protagonista da revolução (Dussel, 1997: 220-221). 
3. Gramsci escreve: "O folclore não deve ser concebido como algo ridículo, como algo estranho que causa risadas, como algo pitoresco; deve ser concebido como algo relevante e deve ser considerado com seriedade. Assim a aprendizagem será mais eficiente e mais formadora sobre a cultura das grandes massas populares" (Gramsci, 1975: 90).

4. Em 1976, antes de Lyotard, usamos o conceito em "Palabras preliminares" de nossa filosofia de la liberación, quando escrevíamos:

"Filosofia da libertação, filosofia pós-moderna, popular, feminista, da juventude, dos oprimidos, dos condenados da terra...".
Nesta época, falava-se de "sujeito histórico" da cultura revolucionária: o "povo" como "bloco social dos oprimidos" quando cobra "consciência subjetiva" de sua função histórica revolucionária (Ramirez, 1982; Arce, 1980).

A cultura popular não era populista. "Populista" implicava a inclusão na "cultura nacional" da cultura burguesa ou oligárquica de sua elite e a cultura do proletariado, do campesinato, de todos os habitantes da terra organizados sob um Estado (na França se denominou "bonapartismo"). O popular, no entanto, seria um setor social de explorados ou oprimidos de uma nação, mas que guardaria também certa "externalidade", como veremos adiante. Oprimidos do sistema estatal, este setor mantém uma alteridade livre nesses momentos culturais, desprezados pelos dominantes apenas como folclore ${ }^{3}$, música, comida, roupas, festivais, a memória de seus heróis, os feitos emancipatórios, as organizações sociais e políticas etc. Como pode ser observada, a visão monolítica substancialista de uma cultura latino-americana havia sido deixada para trás e fissuras culturais internas cresceram graças à mesma revolução cultural.

\section{Modernidade, globalização do ocidentalismo, multiculturalismo liberal e o império militar da "guerra preventiva"}

Lentamente, embora a questão tenha sido vislumbrada intuitivamente desde o final dos anos 1950, passa-se de (a) uma obsessão por "situar" a América Latina na história mundial - o que exigiu reconstruir completamente a visão da denominada história mundial - (b) para o questionamento sobre a visão padrão (geração hegeliana) da mesma história universal que havia nos "excluídos", já que, por ser "eurocêntrica", construía uma interpretação distorcida não só de culturas não europeias, mas, e esta conclusão era imprevisível na década de 1950 e não era esperada a priori, igualmente interpretava equivocadamente a própria cultura ocidental (Dussel, 1995). "Orientalismo" (um defeito da interpretação europeia de todas as culturas ao oriente da Europa, que Edward Said (2007) mostra em sua famosa obra, Orientalismo) foi um defeito coordenado e simultâneo ao "ocidentalismo" (má interpretação da própria cultura europeia). As hipóteses que nos permitiram negar a ausência da cultura latino-americana agora nos levavam à descoberta de uma nova visão crítica das culturas periféricas, e até mesmo da própria Europa. Essa tarefa estava sendo realizada quase simultaneamente em todos os domínios das culturas pós-coloniais periféricas (Ásia, África e América Latina), mesmo se, infelizmente, em menor escala na Europa e nos Estados Unidos.

Na verdade, a partir da problemática "pós-moderna" sobre a natureza da Modernidade - que, em última análise, é uma visão ainda europeia da Modernidade -, começamos a perceber que, o que chamávamos como "pós-moderno" ${ }^{4}$ era algo 
diferente do que aludiam os pós-modernos nos anos 1980 (ao menos davam uma definição diferente do fenômeno da Modernidade daquela que eu havia entendido a partir dos trabalhos realizados para situar a América Latina em confronto com a cultura moderna observada a partir da periferia colonial). Por isso, sentimos a necessidade de reconstruir a partir de uma perspectiva "exterior", ou seja, global (não provinciana, como eram as perspectivas europeias), o conceito de "modernidade", que era - e ainda é -, na Europa e nos Estados Unidos, uma conotação claramente eurocêntrica, desde Lyotard ou Vattimo, até Habermas e, de maneira mais sutil, Wallerstein - que chamamos de "segundo eurocentrismo".

O estudo desta cadeia argumentativa permitiu-nos vislumbrar um horizonte problemático e categórico que relançou o tema da cultura, agora como crítica ao "multiculturalismo liberal" (à maneira de John Rawls, por exemplo, em The law of people), bem como críticas ao otimismo superficial de uma suposta "facilidade" com a qual se expõe a possibilidade de um diálogo multicultural, supondo-o como ingênuo (ou cínico) em uma simetria inexistente entre os argumentadores.

Agora não se tratava mais de uma questão de "situar" a América Latina. Tratava-se de situar todas as culturas que inevitavelmente se enfrentam em todos os níveis da vida cotidiana: a comunicação, a educação, a pesquisa, a política de expansão ou de resistência cultural ou mesmo militar. Sistemas culturais, cunhados por milênios, podem quebrar em décadas, ou se desenvolver pelo choque com outras culturas. Nenhuma cultura tem assegurada a sobrevivência de antemão. Tudo isso tem sido intensificado hoje, momento crucial na história das culturas do planeta.

Em nossa visão no curso da "Hipótese para o estudo da América Latina na história universal", e nos primeiros trabalhos deste período, tendíamos a mostrar o desenvolvimento de cada cultura como um todo independente ou autônomo. Havia "zonas de contato" (como o Mediterrâneo oriental, o Pacífico e as estepes da Eurásia desde Gobi até o Mar Cáspio), mas deixou-se para a expansão portuguesa ao Atlântico Sul e ao Oceano Índico, ou para a "Descoberta América" pela Espanha, o início da implantação do" sistema-mundo" e a conexão pela primeira vez dos grandes "ecúmenos culturais independentes" (a partir de ameríndios, da China, do Hindustão, do mundo islâmico, das culturas bizantina e latino-germânica). A modificação radical desta hipótese por aquela proposta de Andre Gunder Frank - o "sistema de cinco mil anos", (que se impôs de imediato a mim porque refletia minha própria cronologia) - mudou a paisagem. Deve-se reconhecer que houve contatos fortes pelas estepes e pelos desertos do Norte da Ásia (a denominada "rota da seda"): a região da antiga Pérsia foi helenizada em um primeiro momento (em torno de Seleukon, não muito longe das ruínas Babilônia) e, mais tarde, islamizada (Samarkand e Bagdá). Era a "plataforma giratória" do mundo ásio-afro-mediterrâneo. A Euro- 
5. Para os intelectuais do norte da Europa e dos Estados Unidos, desde Habermas até Toulmin, a Modernidade segue aproximadamente este caminho geopolítico: Renaissance (Leste) $\rightarrow$ Reforma Protestante (Norte) $\rightarrow$ Revolução Francesa (Oeste) $\rightarrow$ Parlamentarismo Inglês. A Europa do Mediterrâneo ocidental (Espanha e Portugal) é explicitamente excluída. Trata-se de uma miopia histórica. Mesmo Giovanni Arrighi, que estuda o capital financeiro genovês, ignora que esta era a época do Império Espanhol (e não vice-versa). Ou seja, a Itália renascentista era ainda mediterrânea (antiga), já Espanha era atlântica (moderna).

6. René Descartes foi aluno de La Flèche, escola jesuíta, e reconhece que a primeira obra filosófica que ele leu foi Disputaciones metafísicas, de Francisco Suárez (ver Dussel, 2007).

\section{Não se} esquecendo que o cavaleiro medieval - Dom Quixote enfrenta os moinhos, que são o símbolo da modernidade (moinhos procedentes do mundo islâmico: Bagdá empregava moinhos de vento desde século VIII d.c.). pa latino-germânica foi sempre periférica (embora ao sul tivesse seu próprio peso devido à presença do antigo Império Romano), mas nunca foi "centro" desta vasta massa continental. O mundo muçulmano (desde Mindanao, nas Filipinas, Malaka, Delhi, o "coração do mundo" muçulmano, até o Maghreb com Fez no Marrocos ou a Andaluzia de Averroes, Córdoba) era uma cultura mercantilista muito mais desenvolvida (científica, teórica, econômica e culturalmente) do que a Europa latino-germânica depois da catástrofe das invasões germânicas, e as invasões islâmicas do século VII d.C. (Dussel, 2000: 465-478). Diversamente do que afirma Max Weber, deve ser aceita uma diferença civilizatória até o século XIII (as invasões turcas siberianas destroçaram a grande cultura árabe) entre a futura cultura europeia (ainda não desenvolvida) e a cultura islâmica.

No Ocidente, a "Modernidade", que começa com a invasão da América pelos espanhóis, cultura herdada dos muçulmanos do Mediterrâneo (Andaluzia) e do Renascimento italiano (pela presença Catalã, no sul da Itália5), é a "abertura" geopolítica da Europa para o Atlântico; é a implantação e o controle do "sistema-mundo" no sentido estrito (pelos oceanos e não mais pelas caravanas continentais lentas e perigosas) e ainda a "invenção" do sistema colonial, que, por 300 anos, irá inclinar lentamente o equilíbrio econômico-político em favor da antiga Europa isolada e periférica. Tudo o que é simultâneo com a origem e o desenvolvimento do capitalismo (mercantil a princípio, de mera acumulação primitiva de dinheiro), ou seja, a Modernidade, o colonialismo e o sistema-mundo, denota aspectos de uma mesma realidade simultânea e mutuamente constitutiva.

Se assim é, então a Espanha é a primeira nação moderna. Essa hipótese se opõe a todas as interpretações da Modernidade, da Europa Central e dos Estados Unidos, e é até mesmo contrária à opinião da grande maioria dos intelectuais espanhóis de hoje. No entanto, estas ideias impõem-se a nós com cada vez mais força, à medida que encontramos novos argumentos. De fato, a Primeira Modernidade, a Ibérica (1492-1630 aproximadamente), tem nuances muçulmanas na Andaluzia (a região foi a mais culta do Mediterrâneo no século XII) inspirada pelo humanismo renascentista italiano, firmemente implantado pela contrarreforma do cardeal Cisneros, pela reforma universitária dos dominicanos de Salamanca (cuja Segunda Escolástica já é "moderna" e não meramente medieval) e, logo depois, pela cultura barroca jesuíta, na figura filosófica de Francisco Suarez, que inaugura o pensamento metafísico moderno (AI-Yabri, 2001a; 2001b) ${ }^{6}$. Dom Quixote é a primeira obra literária moderna de seu tipo na Europa, cujos personagens têm cada pé em um mundo diferente: ao sul islâmico e ao norte cristão, na cultura mais avançada de sua época, iniciando a Europa moderna ${ }^{7}$. A primeira gramática de uma língua românica era espanhola, editada por Nebrija, em 1492. Em 1521, a primeira revolução burguesa de Castela é esmagada por Carlos $\vee$ (os moradores lutavam para defender suas jurisdições urbanas). 
A primeira moeda de prata mundial foi cunhada no México e no Peru, passando por Sevilha e, eventualmente, entesourada na China. É uma Modernidade mercantil, pré-burguesa, humanista, que começa a expansão europeia.

Apenas na Segunda Modernidade é desenvolvido nas Províncias Unidas dos Países Baixos - província espanhola até início do século XVII - um novo desenvolvimento da Modernidade, agora devidamente burguesa (1630-1688). A Terceira Modernidade, inglesa e, mais tarde, francesa, expande o modelo anterior - filosoficamente iniciado por Descartes e Espinosa, desdobrando-se para uma coerência mais prática, a partir do individualismo possessivo de Hobbes, Locke e Hume (Wallerstein, 1974; 1980; 1989).

Com a Revolução Industrial e o lluminismo, a Modernidade atingiu sua plenitude, financiada pelo colonialismo, expandindo-se pelo Norte da Europa, pela Ásia e, depois, pela África.

A Modernidade teria cinco séculos - assim como o "sistema-mundo" - e também foi coextensiva com o domínio europeu sobre o planeta, da qual tornou-se o "centro" a partir de 1492. A América Latina, assim, foi um momento constitutivo da Modernidade. O sistema colonial não podia ser feudal - questão central para as ciências sociais em geral, desenvolvida por Sergio Bagú (1949) - senão periférico de um mundo capitalista moderno, portanto, ele mesmo moderno.

Neste contexto, faz-se a crítica à posição ingênua que definia o diálogo entre culturas como possibilidade multicultural simétrica, em parte idealizada e na qual a comunicação parecia ser possível para os seres racionais. A "ética do discurso" adotava esta posição otimista. Richard Rorty, de forma distinta àquela desenvolvida por Alasdair Mclntyre, mostrava a completa incomensurabilidade de uma comunicação impossível ou sua extrema dificuldade. De qualquer forma, era necessário situar as culturas (sem nomeá-las concretamente nem estudar sua história e seu conteúdo estrutural) em uma situação assimétrica que se originava a partir de suas respectivas posições no próprio sistema colonial. A cultura ocidental, com seu evidente "ocidentalismo", alocava todas as demais culturas como mais primitivas, como pré-modernas, tradicionais e subdesenvolvidas.

No momento em que se desenvolve uma teoria do "diálogo entre as culturas" parecia que todas as culturas teriam condições simétricas. Ou por meio de uma "antropologia" ad hoc que realizava a tarefa de observação descomprometida (ou, no melhor dos casos, "comprometida") das culturas primitivas. Neste caso, existem as culturas superiores (do "antropólogo cultural" acadêmico) e "as outras" (primitivas). Entre esses dois extremos estão as culturas desenvolvidas simetricamente e 
8. Consenso justaposto ou consenso sobreposto. (n. do t.) "as outras" (que sequer podem ser situadas assimetricamente, em razão do abismo cultural intransponível). É o caso de Durkheim ou Habermas. Diante da posição de observação da antropologia não pode haver diálogo cultural com a China, com a Índia, com o mundo islâmico etc., que não são culturas ilustradas nem primitivas. Estão na "terra de ninguém".

Essas culturas, que não são nem "metropolitanas" nem "primitivas", vão sendo destruídas por meio de propaganda, a partir da venda de mercadorias e de bens materiais que são sempre produtos culturais (tais como bebidas, alimentação, vestuário, veículos etc.), mesmo se, por outro lado, há uma tentativa de salvá-las valorizando seu isolamento, seus elementos folclóricos ou momentos culturais secundários. A transnacionalização da alimentação pode subordinar entre seus cardápios um prato próprio de uma cultura culinária (como "Taco Bell”). Este processo se passa por "respeito" às outras culturas.

Este tipo de multiculturalismo altruísta está claramente formulado no overlapping consensus $^{8}$ de John Rawls, que exige a aceitação de certos princípios processuais (que são profundamente culturais e ocidentais) que devem ser aceitos por todos os membros de uma comunidade política, permitindo, ao mesmo tempo, a diversidade cultural valorativa (ou religiosa). Politicamente, isso supõem que aqueles que estabelecem o diálogo aceitem o Estado liberal multicultural, sem perceber que a própria estrutura deste Estado multicultural, tal como está institucionalizada no presente, é a expressão da cultura ocidental e restringe a possibilidade de sobrevivência de todas as demais culturas. Sub-repticiamente, impõe-se uma estrutura cultural em nome de elementos puramente formais de convivência (que tem sido uma expressão do desenvolvimento de uma cultura particular). Além disso, não se tem clara consciência de que a estrutura econômica deste processo é o capitalismo transnacional, que funda este tipo de Estado liberal, e que limita nas culturas "incorporadas", graças ao indicado pelo overlapping consensus (ação de esvaziamento prévio dos elementos críticos anticapitalistas dessas culturas) diferenças antiocidentais inaceitáveis. Este tipo de diálogo asséptico multicultural (frequentemente também entre as religiões universais), torna-se, em certos casos, uma política cultural agressiva, como Huntington (1996), em seu livro The clash of civilizations, advoga diretamente, em defesa da cultura ocidental mediante a utilização de instrumentos militares, especialmente contra os fundamentalistas islâmicos, habitantes de uma região cujo subsolo se caracteriza pelas maiores reservas de petróleo do planeta (e sem se referir à presença do fundamentalismo cristão, especialmente nos Estados Unidos, de igual signo e estrutura). Novamente não se adverte que o "fundamentalismo de mercado", como denomina Georg Soros, institui esse fundamentalismo militar agressivo, das "guerras preventivas", que se disfarça como choques culturais ou expansão de uma cultura política democrática. Tem se passado, portanto, de (a) 
um pretenso diálogo simétrico do multiculturalismo para $(b)$ a supressão pura e simples de todo diálogo e a imposição, pela força, da tecnologia militar da própria cultura ocidental, ao menos este é o pretexto, já que sugerimos que se trata tão somente do cumprimento dos interesses econômicos pelo petróleo, como demonstrou a Guerra do Iraque.

Em sua obra Império, Negri e Hardt sustentam certa visão pós-moderna da estrutura globalizada do sistema-mundo. É necessário antepor esta visão a uma interpretação que permita compreender com mais profundidade a conjuntura atual da história mundial, sob a hegemonia militar do Estado norte-americano (o home-State das grandes corporações transnacionais), que vai transformando os Estados Unidos em império, um tipo de dominação posterior ao fim da Guerra Fria (1989), que tenta encaminhar uma gestão monopolar de poder global. O diálogo multicultural ficou certamente reduzido apenas à visão ingênua das assimetrias entre dialogantes? Como é possível imaginar um diálogo diante de tamanha distância de possibilidade para suportar os instrumentos tecnológicos de um capitalismo baseado na expansão militar? Não estará tudo perdido se a imposição de certo ocidentalismo, cada vez mais identificado com o "americanismo" (estadunidense, obviamente), apagar da face da terra todas as culturas do mundo que se desenvolveram no último milênio? Não é o inglês a única língua clássica que a humanidade importará, que sobrecarregada deve até mesmo esquecer as suas próprias tradições?

\section{Transversalidade do diálogo intercultural transmoderno: libertação mútua das culturas universais pós-coloniais}

Assim, chegamos à fase final de maturação, a partir das novas hipóteses de Andre Gunder Frank (1998). Sua obra ReOrient: global economy in the Asian age (e a argumentação mais complexa de Kenneth Pomeranz (2000) em The great divergence: China, Europe and the making of the modern world economy ${ }^{9}$ ) novamente nos permite implantar uma problemática ampliada e críticas que devem retomar chaves de interpretações para o problema da cultura da década de 1960, alcançando agora uma nova aplicação que queremos denominar como "transmoderna" - superação explícita do conceito de "pós-modernidade" (pós-modernidade ainda é um momento final do modernidade).

A nova hipótese de trabalho pode ser formulada da seguinte maneira, e muito simplificadamente: a Modernidade (o capitalismo, o colonialismo, e o primeiro sistema-mundo) não é contemporânea à hegemonia global da Europa - desempenhando um papel de "centro" do mercado no que diz respeito às culturas restantes. "Centralidade" do mercado mundial e Modernidade não são fenômenos sincrônicos. A Europa moderna torna-se "centro" depois de ser "moderna". Para Wallerstein, ambos
9. Nesta obra, Pomeranz comprova que efetivamente que, até 1800 , a Inglaterra não tinha qualquer progresso significativo em relação ao Delta do rio Yangtze, na China (habitado por 39 milhões de pessoas, em 1750), e que, depois de avaliar novos argumentos sobre o desenvolvimento ecológico do uso da terra em ambas as regiões, atribuiu a possibilidade da Revolução Industrial se dar na Inglaterra, devido a dois fatores externos, ou fortuitos, ao sistema econômico inglês: ter colônias e carvão. Nenhum outro fator permitiu esta vantagem inicial mínima da Inglaterra sobre a região do Delta do Yangtze que, na sequência, se tornaria enorme. O autor desconsidera mesmo a crise econômica na China ou no Hindustão. O uso crescente e antiecológico da terra na China exigiu uma maior mão de obra campesina, o que impediu o surgimento da indústria capitalista na região, simultaneamente à inglesa. 
10. Da Revolução Francesa à queda da União Soviética, o que significa a ascensão monopolar da hegemonia norteamericana, após o fim da Guerra Fria. os fenômenos são coextensivos (por isso posterga a Modernidade e sua centralidade no mercado mundial até o "Iluminismo" e a ascensão do liberalismo). De minha parte, acredito que os quatro fenômenos (sistema-mundo, capitalismo, colonialismo e Modernidade) são contemporâneos (mas não a "centralidade" do mercado mundial). Hoje, então, devo salientar que, até 1789 (para dar uma data simbólica para o final do século XVIII) a China e a região do Hindustão tinham um enorme peso produtivo-econômico no "mercado mundial" (que produzia os bens mais importantes desse mercado tais como porcelana, tecidos de seda etc.) e que a Europa não poderia de modo algum igualar-se. A Europa não podia vender nada no mercado do Extremo Oriente. Só foi capaz de comprar no chamado mercado chinês durante três séculos, graças à prata da América Latina (principalmente do Peru e do México).

A Europa começou a ser "centro" do mercado mundial (e através dele estender o "sistema-mundo" por todo o planeta) a partir da Revolução Industrial. No plano cultural, produziu o fenômeno do lluminismo, cuja origem, no longo prazo, devemos encontrar (segundo as hipóteses que consideraremos seguindo o filósofo marroquino Al-Yabri) na filosofia averroísta do Califado de Córdoba. A hegemonia central e ilustrada da Europa tem apenas dois séculos (1789-1989) ${ }^{10}$. Apenas dois séculos! Período demasiadamente curto para transformar com profundidade o "núcleo ético-mítico" - para nos expressarmos como Ricœur - das culturas universais e milenares, como a chinesa e outras mais do Extremo Oriente (como a japonesa, a coreana, a vietnamita etc.), a hinduísta, a islâmica, a bizantino-russa, e até mesmo a bantu ou as da América Latina (de diferente composição e estrutura). Essas culturas foram, em parte, colonizadas, mas a maior parte de suas estruturas de valores foram sobretudo excluídas, desprezadas, negadas, ignoradas mais do que aniquiladas. O sistema econômico e político foi dominado no exercício do poder colonial e da acumulação gigantesca de riqueza, mas essas culturas têm sido interpretadas como desprezíveis, insignificantes, sem importância e inúteis. Esse desprezo, no entanto, permitiu-Ihes sobreviver em silêncio, desdenhadas simultaneamente por suas próprias elites modernizadas e ocidentalizadas. Essa alteridade negada, sempre existente e latente, indica a existência de uma riqueza cultural insuspeita, que renasce lentamente como chamas de carvão enterrado no mar de cinzas centenárias do colonialismo. Essa exterioridade cultural não é uma mera "identidade" substantiva não contaminada e eterna. Ela tem evoluído diante da própria Modernidade; trata-se de uma "identidade" em processo de crescimento, mas sempre como uma exterioridade.

Essas culturas universais assimétricas - espelho de suas condições econômicas, políticas, científicas, tecnológicas, militares - guardam uma alteridade em relação à Modernidade europeia, com a qual conviveram e aprenderam a responder à sua maneira aos desafios. Não estão mortas, mas vivas, e, atualmente, em pleno proces- 
so de renascimento, buscando (e inevitavelmente equivocando-se) novos caminhos para o desenvolvimento de seu futuro próximo. Por não serem modernas, essas culturas não podem ser "pós"-modernas. São pré-modernas (anteriores à Modernidade), contudo contemporâneas à Modernidade e logo serão transmodernas. O pós-modernismo é uma fase final da cultura moderna euro-americana, o "centro" da Modernidade. As culturas chinesa e vedanta não poderão jamais ser pós-moderno-europeias, e sim outra coisa bem diferente e a partir de suas próprias raízes.

Assim, o conceito estrito de "transmoderno" indica essa novidade radical que significa o surgimento - como se a partir do nada - da exterioridade, da alteridade, do sempre distinto, de culturas universais em desenvolvimento, que assumem os desafios da Modernidade e, até mesmo, da pós-modernidade euro-americana, mas que respondem a partir de outro lugar, other location (Dussel, 2002), do ponto de sua própria experiência cultural, diferente da euro-americana, portanto capaz de responder com soluções completamente impossíveis para a cultura moderna única. Uma futura cultura transmoderna, que assume os momentos positivos da Modernidade (mas avaliados com critérios diferentes a partir de outras culturas antigas), terá uma pluriversalidade rica e será fruto de um autêntico diálogo intercultural, que deverá ter claramente em conta as assimetrias existentes. Um mundo pós-colonial e periférico, como o da Índia, em completa assimetria em relação ao centro metropolitano da era colonial, sem deixar de ser um núcleo criativo de renovação de uma cultura milenar e decisivamente distinta de qualquer outra, capaz de propor respostas inovadoras e necessárias para os desafios angustiantes que o planeta nos lança no início do século XXI.

"Transmodernidade" indica todos os aspectos que se situam "além" (e também, cronologicamente, "anteriores") das estruturas valorizadas pela cultura euro-americana moderna, e que atualmente estão em vigor nas grandes culturas universais não europeias e foram se movendo em direção a uma utopia pluriversal.

O diálogo intercultural deve ser transversal ${ }^{11}$, ou seja, deve partir

\section{ESQUEMA 1}

MODELO APROXIMADO PARA COMPREENDER O SENTIDO DA TRANSMODERNIDADE

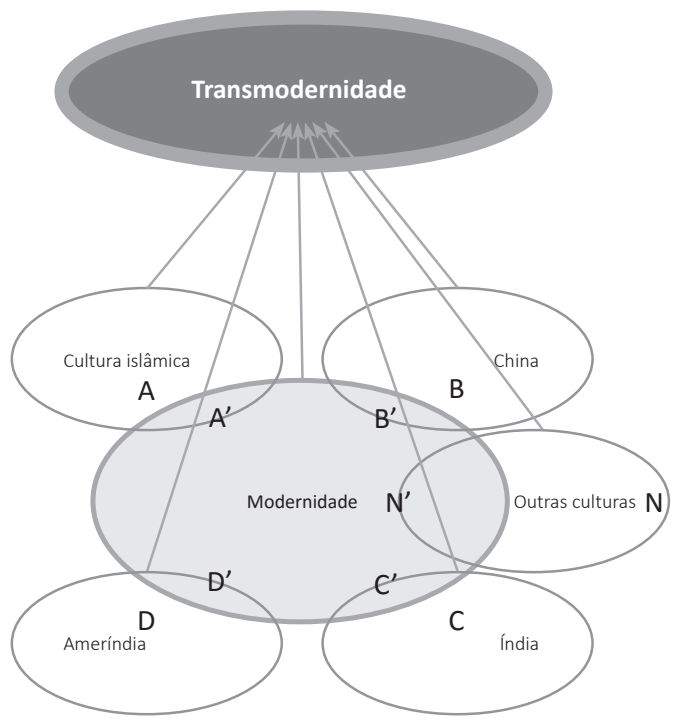

11. "Transversal" indica aqui que o movimento se dá a partir da periferia para a periferia. Do movimento feminista às lutas antirraciais e anticoloniais, as "diferenças" dialogam a partir de suas várias negatividades, distintas, sem necessidade de atravessar o "centro" da hegemonia. Frequentemente, as grandes cidades têm grandes serviços subterrâneos que vão dos bairros dos subúrbios para o centro; mas faltam conexões entre os subcentros suburbanos. Por analogia, acontece exatamente o mesmo com o diálogo intercultural. 
12. O árabe, depois de séculos de traduções gregas das obras filosóficas helênicas, teve de inventar uma linguagem filosófica técnica absolutamente sofisticada. Portanto, desde o Marrocos às Filipinas, a filosofia do mundo muçulmano deve ser chamada de "filosofia árabe", o nome de sua língua clássica.

13. Quando perguntado

"como recuperar a glória de nossa civilização? Como dar nova vida à nossa herança?". Al-Yabri responde com uma exigente descrição das respostas ambíguas, parciais ou eurocêntricas. Os salafies foram originados pela posição de Jamal al-Din al-Afghani (1897), que lutou contra os britânicos no Afeganistão, viveu em Istambul, refugiou-se no Cairo e fugiu para Paris. Este movimento visa libertar e unificar o mundo islâmico. de outro lugar, para além do mero diálogo entre eruditos do mundo acadêmico ou institucionalmente dominante. Deve haver um diálogo multicultural que não pressupõe a ilusão de simetria inexistente entre as culturas. Aqui estão alguns aspectos críticos do diálogo intercultural em relação à transmodernidade.

Tomemos como fio condutor de nossa exposição uma obra da cultura islâmica no campo filosófico. Mohamed Abed Al-Yabri (2001a; 2001b), em suas obras Crítica de la razón árabe e El legado filosófico árabe, é um excelente exemplo do que esperamos explicar. Al-Yabri, filósofo do Magreb, ou seja, de uma região cultural sob a influência do pensamento do Califado de Córdoba em sua idade clássica, começou a desconstrução de sua tradição árabe ${ }^{12}$, culminando em um autêntico "iluminismo" filosófico, antecedente direto do Renascimento latino-germânico de Paris do século XIII, e é ainda um antecedente direto do Aufklärung europeu do século XVIII (de ascendência "averroísta", de acordo com a hipótese de Al-Yabri).

\section{Afirmação de exterioridade desprezada}

Tudo começa com uma afirmação. A negação da negação é o segundo momento. Como se poderá negar o desprezo de si mesmo, senão iniciando pelo caminho para o autodescobrimento do próprio valor? A afirmação de uma "identidade" processual e reativa diante da própria Modernidade. As culturas pós-coloniais devem efetivamente se decolonizar, mas devem começar pela autovaloração.

Há diferentes maneiras de autoafirmar-se, dentre elas formas equivocadas da própria afirmação. Assim, a partir do exemplo inicialmente adiantado, Al-Yabri critica as próprias interpretações ou "leituras" hermenêuticas da tradição islâmica da filosofia árabe contemporânea no mundo muçulmano. A primeira linha de interpretação é a do fundamentalismo ("salafismo"13). Essa interpretação tem uma intenção afirmativa, como todas as demais, já que tenta recuperar a antiga tradição árabe no presente. Mas, para Al-Yabri, essa corrente é a-histórica, meramente apologética e tradicionalista (Al-Yabri, 2001b). Outra linha de interpretação é a liberal, pró-europeia, destina-se a ser meramente moderna, mas, em última análise, nega o passado ou não sabe como reconstruí-lo. A terceira interpretação é de esquerda (o "salafismo marxista"). A questão, diante dessas três hermenêuticas presentes no passado, é: "De que modo [podemos] reconstruir [hoje] o nosso legado?" (Al-Yabri, 2001b: 24).

O primeiro passo é estudar esse legado afirmativamente. Al-Yabri, leitor com domínio do árabe como língua materna, e aprendiz desde a infância da cultura islâmica, tem uma enorme vantagem sobre todos os peritos europeus e norte-americanos que estudam o mundo árabe como "objeto" científico e como cultura "estrangeira". Ao ler os clássicos, vislumbrou nuances desconhecidas, e o faz a partir da filosofia 
hermenêutica francesa contemporânea que tem sido estudada por todo o Magreb. Expõem positivamente o pensamento de Al-Farabi, Avicena, Avempace, Averróis, Abenjaldún, mas não apenas como afirmação ingênua ou apologética.

Em termos de cultura popular, outro exemplo: Rigoberta Menchú (1995), em Me llamo, Rigoberta Menchú y así nasció la conciencia, dedica longos capítulos para descrever a cultura do povo maia da Guatemala. Parte de uma afirmação autovalorativa e é a partir desta reflexão inicial que edificará todo um edifício. Contra os juízos já habituais é necessário começar desde a origem positiva da própria tradição cultural. Esta primeira etapa é uma recordação do passado, a partir de uma identidade anterior à Modernidade, ou que vem evoluindo de forma imperceptível no contato inevitável e secreto com a Modernidade.

\section{A crítica da própria tradição \\ a partir dos recursos de sua própria cultura}

Mas a única maneira de crescer a partir de sua própria tradição é fazer uma crítica a partir dos pressupostos da própria cultura. É necessário encontrar nela os momentos originários de uma autocrítica.

Assim, Al-Yabri faz uma "desconstrução" de sua tradição com elementos críticos de sua e de outras perspectivas da própria Modernidade. Não é a Modernidade que impõe ao intelectual os instrumentos críticos; é o intelectual crítico que controla, administra e escolhe os instrumentos modernos que serão úteis para a reconstrução crítica de sua própria tradição. Al-Yabri mostra que as escolas "orientais" do mundo árabe (as escolas relacionadas a Bagdá são as propriamente orientais, mais próximas do gnosticismo persa; aquelas mais associadas ao Cairo, de tradição neoplatônica alexandrina, já são ocidentais na esfera do Oriente islâmico, como veremos adiante) opunham-se, inicialmente, ao seu principal inimigo: o pensamento gnóstico persa. Os Mu'tazilites criaram o primeiro pensamento teórico islâmico (antipersa), com componentes próprios do Corão, integrando também de maneira criativa a cultura greco-bizantina, a fim de justificar a legitimidade política do Estado califal ${ }^{14}$. Assim nasceram as tradições orientais. A escola abacída (em Bagdá e nas regiões vizinhas, como Samarkand e Bukhara), mas também a tradição fatímida (no Cairo), com pensadores como Al-Farabi e Avicena, inclinaram-se, no entanto, para um pensamento neoplatônico com conotações teológicas e místicas como a "iluminação". Em contrapartida, Al-Yabri ensina, de forma diversa a muitos expositores da história e da filosofia árabe, que a filosofia propriamente ocidental de Andalus-Magreb (em torno das grandes capitais culturais de Córdoba ao norte e Fez ao sul, que chegou a ter mais de 300 mil habitantes no século XIII) significou uma ruptura inicial que teria um legado duradouro. Tanto por razões políticas como econômicas (e aqui
14. De maneira altamente original e legítima, Al-Jabri mostra que "as ciências filosóficas gregas" transformaram-se em filosofia, teologia e jurisprudência islâmica graças a quatro correntes filosóficas:

"A primeira é representada por tradutores e secretários de origem iraniana [...], o modelo oriental (persa) do neoplatonismo.

A segunda é

representada por médicos e tradutores cristãos que chegaram da escola persa de Yundisapur [... que,] além de professores nestorianos, recebeu um grupo de professores da escola de Atenas [...] o modelo neoplatônico ocidental. A terceira corrente [a mais importante], a oriental, é representada pelos tradutores professores e estudiosos originários da antiga cidade de Harrán, ao norte da Mesopotâmia. [...]. A quarta, a ocidental, é a que finalmente aparece com a chegada da Academia de Alexandria" (AlYabri, 2001b: 177). A Academia foi criada no território dos sabeus. Esta escola é fundamental, já que significou uma síntese do pensamento persa, neoplatônico e aristotélico (Al-Yabri, 2001b: 165), questão 
pouco estudada fora do mundo filosófico árabe, já que requer uma bibliografia sem traduções para as línguas ocidentais. Os "Irmãos da Pureza" são da linhagem da tradição de Harrán.

15. Para Avempace, a perfeição humana não consiste na contemplação estática do sufismo, mas na vida do "homem solitário", que, na cidade imperfeita, anseia pela cidade perfeita, pelo estudo racional das ciências filosóficas. O ato de "intelecto agente" por excelência, o conhecimento dos sábios são espirituais e divinos. Al-Yabri (2001b) dedica excelentes páginas a Avempace, em seu tratado sobre a felicidade dos sábios, inspirado e desenvolvido a partir de Aristóteles (ver Dussel, 1994: 297314). o filósofo marroquino utiliza ferramentas críticas da filosofia moderna europeia), o Califado de Córdoba ocidental, como já indicado, quebrou a visão teológica do pensamento oriental e inaugurou uma distinção clara entre a razão natural (que se conhece cientificamente pela observação e desenvolve de uma nova forma a física, a mecânica e a matemática) e a razão iluminada pela fé. Distingue-se razão e fé, não as confunde nem as nega. Estas são articuladas de uma nova maneira.

Foi o filósofo Ibn Abdun que levou os filósofos do Al-Andalus à orientação racionalista da escola de Bagdá (contrária à posição de Al-Kindi, Al-Farabi e Avicena). Uma segunda geração - no início do século $V$ da hégira (século XI cristão) -, especializa -se em matemática e medicina. A terceira geração, com Avempace, integra a física e a metafísica aos objetos de estudo e se liberta do neoplatonismo gnóstico da escola oriental, já invocando a argumentação racional aristotélica - extraída de neoplatonismo (Al-Yabri, 2001b: 226) ${ }^{15}$.

Os Almohades tinham por lema cultural: "Abandonar o argumento de autoridade e voltar às fontes". Trata-se, de um movimento cultural liderado por Ibn Tumart, em um período de grandes mudanças, portanto, de grande liberdade política e com um ímpeto racional e crítico. Ibn Tumart critica a analogia como método que vai do conhecido para o desconhecido (Al-Yabri, 2001b: 323). Se Al-Farabi e Avicena (pela multiplicidade e os problemas políticos do Oriente) pretendiam unir filosofia e teologia, Averróis está propondo separá-las, mas mostrando a sua mútua autonomia e complementaridade. Esse foi o tema de sua obra Doctrina decisiva y fundamento de la concordia entre la revelacion y la ciencia, um verdadeiro Discurso do método. A verdade (revelada) não pode contradizer a verdade (racional), e vice-versa. Especificamente em A destruição da destruição Averróis mostra que Al-Ghazali não se utiliza de argumentos apodícticos para tentar demonstrar a irracionalidade da filosofia. $\mathrm{Na}$ sequência, houve o desenvolvimento e a expressão de toda a doutrina chamada "dupla verdade" de Averróis, que foi equivocadamente interpretada no mundo latino medieval, mesmo influenciando decisivamente a origem da ciência experimental na Europa mediante o chamado "averroísmo latino". Ao mesmo tempo o filósofo de Córdoba indicou a maneira de se relacionar com as demais culturas:

É claro que devemos servir como apoio para o nosso estudo (racional dos seres existentes) das investigações realizadas por todos os que nos precederam [os gregos] [...]. Assim como realmente os filósofos antigos estudaram com muito cuidado as regras de raciocínio (lógica, método), convém a nós trabalharmos para estudar os livros dos chamados filósofos antigos, para que, se tudo o que dizem considerarmos razoável, aceitá-lo; e se algo houver de irrazoável, nos sirva de precaução e advertência (Al-Yabri, 2001a: 157-158). 
Para Al-Yabri, "adotar o espírito averroísta é romper com o espírito avicenista oriental, gnóstico e obscurantista" (Al-Yabri, 2001a: 159). Como se pode ver, a filosofia árabe praticou o método que estamos descrevendo: foi fiel à sua tradição, mas a subordinou ao melhor (segundo seus próprios critérios) de outra cultura que, de certa forma, era considerada altamente desenvolvida (por exemplo, no desenvolvimento da ciência lógica).

Rigoberta Menchú, da mesma forma, questiona, entre as comunidades indígenas irmãs, a causa de sua passividade, o fatalismo, e inicia uma crítica comunitária que os levará a se comprometer na luta contra o governo mestiço e a repressão militar.

Dessa forma, o intelectual crítico deve ser alguém localizado "entre" (in betweeness) as duas culturas (a sua e a moderna). Essa é a questão da border (fronteira) entre duas culturas, como lugar de um "pensamento crítico". Esta questão está detalhadamente exposta por Walter Mignolo, no caso da fronteira México-Estados Unidos, como ambiente bicultural criativo.

\title{
Estratégia de resistência. \\ O tempo hermenêutico
}

Para resistir, é necessário amadurecer. A afirmação dos próprios valores exige tempo, estudo, reflexão, retorno aos textos ou símbolos e mitos constitutivos de sua própria cultura, antes ou ao mesmo tempo do domínio dos textos da cultura hegemônica moderna.

Al-Yabri mostra o equívoco de alguns intelectuais árabes, cuja relação com o legado cultural europeu parece ser mais estreita do que a que possuem com a herança árabe-islâmica, colocando o problema do pensamento árabe contemporâneo nos seguintes termos: Como este pensamento pode assimilar a experiência do liberalismo antes ou sem que o mundo árabe passe pela etapa do liberalismo?" (Al-Yabri, 2001a). Abdalah Laroui, Zaki Nayib Mahmud, Mayid Fajri e tantos outros levantaram dessa forma a questão. O problema, no entanto, é outro:

\begin{abstract}
Como o pensamento árabe contemporâneo pode recuperar e assimilar a experiência racionalista de seu próprio legado cultural para vivê-la novamente, em uma perspectiva semelhante à de nossos antepassados: lutar contra o feudalismo, contra o gnosticismo, contra o fatalismo e estabelecer a urbe da razão e da justiça, uma urbe árabe livre, democrática e socialista? (Al-Yabri, 2001a: 160).
\end{abstract}

Como se pode constatar, um projeto desta envergadura requer tenacidade, tempo, inteligência, investigação, solidariedade. Trata-se de um longo período de amadu- 
recimento de uma nova resposta da resistência cultural, e não apenas de coabitação com outras elites de outras culturas, especialmente as dominantes, senão contra o eurocentrismo de suas próprias elites da mesma cultura periférica, colonial, fundamentalista.

Rigoberta Menchú, por sua vez, mostra como exemplo sua reinterpretação sobre a comunidade. Ao ir tomando consciência crítica, o cristianismo tradicional permitiria justificar as lutas das comunidades contra a dominação das elites brancas militarizadas na Guatemala. Trata-se de uma nova hermenêutica do texto constitutivo da vida cultural da comunidade, o que, em nível simbólico, é fundamental para os ameríndios, que manifestam uma vertente maia articulada à vertente colonial-cristã.

\section{O diálogo intercultural entre os críticos de sua própria cultura}

O diálogo intercultural não é apenas - ou principalmente - um diálogo entre os apologistas de suas culturas, que tentaram mostrar aos outros as virtudes e os valores de sua própria cultura. É, sobretudo, um diálogo entre os críticos de sua própria cultura (intelectuais da "fronteira" entre a própria cultura e a Modernidade). Não são os que simplesmente a defendem de seus inimigos, mas que primeiramente a recriam a partir de pressupostos críticos que se encontram em sua própria tradição cultural e da mesma Modernidade que se globaliza. A Modernidade pode servir como catalisador crítico (se utilizada pela mão especialista de críticos da própria cultura). No entanto, não é um diálogo entre os críticos do "centro" e os críticos da "periferia" cultural. É, sobretudo, um diálogo entre os "críticos da periferia", um diálogo intercultural Sul-Sul, antes de ser um movimento para o diálogo Sul-Norte.

Este diálogo é essencial. Como filósofo latino-americano, gostaria de começar uma conversa com Al-Yabri a partir da seguinte pergunta: Por que o pensamento filosófico islâmico caiu em uma crise tão profunda a partir do século XIV? Isto não se explica apenas pela presença lenta e crescente do Império Otomano. Por que essa filosofia foi imersa pelo impasse do pensamento fundamentalista? Temos de recorrer a uma interpretação histórico-mundial mais ampla para compreender que, tendo sido o mundo islâmico a "chave" de contato com "mundo antigo" (a partir de Bizâncio, e em menor parte, da Europa latino-germânica até o Hindustão e a China), a constituição do "sistema-mundo" tendeu para a Espanha e Portugal, para o domínio dos oceanos, deixando lentamente o mundo muçulmano fora da zona central de contato com as demais culturas universais (como havia sido no "mundo antigo"). A perda de "centralidade" (e, assim, de "informação"), o empobrecimento relativo (mesmo que apenas pela inflação da prata diante da enorme quantidade extraída da América Latina) e outros fatores não necessariamente culturais ou filosóficos mergulharam o mundo árabe em uma pobreza "periférica", em uma divisão e em 
um isolamento político que o "tribalizou", desarticulando-o em separatismos destrutivos nas antigas regiões unificadas pelo direito, pela religião, pela ciência, pelo comércio e pela língua árabe.

A decadência filosófica foi apenas um momento do declínio de uma civilização, de uma crise econômica, política e militar de um mundo que de "centro" tornou-se "periferia". Há, então, de relacionar, por exemplo, a história do mundo islâmico com o nascimento do "sistema-mundo", com a América Latina e com o crescimento da Modernidade europeia, equidistante ao peso da cultura hindu-chinesa até os anos 1800. Isso permitiu, no século XIX, ou seja, após a Revolução Industrial, a "colonização" do mundo árabe. A colonialidade cultural se expressa filosoficamente pela decadência filosófica. Salazar Bondy perguntava-se de maneira semelhante na América Latina em 1969: "É possível pensar filosoficamente e criativamente a partir de um ser colonial?" (Bondy, 1969).

No caso de Rigoberta Menchú, o diálogo mais fértil é realizado pelos críticos de cada comunidade com outras comunidades, e das comunidades indígenas com os críticos do mundo mestiço e latino-americano hegemônico. Rigoberta transforma-se em uma interlocutora de muitas vozes, muitas reivindicações: das feministas, dos ecologistas, dos movimentos antirracistas etc.

Com essa capacidade de se fertilizarem transversalmente, mutuamente, os pensadores críticos da periferia e dos espaços de "fronteira" consolidam o fruto do diálogo intercultural. Ao organizarem redes de discussão de seus problemas específicos, o processo de afirmação torna-se uma arma de libertação. Temos de nos informar e aprender com os fracassos, as conquistas e a justificação, mesmo que teórica, do processo de criação diante da globalização da cultura europeia e norte-americana, cuja pretensão de universalidade deve ser desconstruída a partir da perspectiva multifocal de cada cultura.

\section{Estratégia de crescimento libertador transmoderno}

Uma estratégia pressupõe um projeto. Denominamos projeto "transmoderno" a tentativa libertadora que resume tudo o que temos dito. Em primeiro lugar, a afirmação é indicada como valorização de seus próprios momentos culturais negados ou simplesmente depreciados que se encontram na exterioridade da modernidade; que foram deixados de fora da consideração destrutiva desta pretensa cultura moderna universal. Em segundo lugar, esses valores tradicionais ignorados pela Modernidade devem ser o ponto de partida de uma crítica interna, a partir das possibilidades hermenêuticas próprias dessas culturas. Em terceiro lugar, os críticos, para serem críticos, devem viver o biculturalismo das "fronteiras" e então criar um pen- 
samento verdadeiramente crítico. Em quarto lugar, esse processo supõe um período longo de resistência, de amadurecimento e de acumulação de forças. É tempo do cultivo acelerado e criativo do desenvolvimento da própria tradição cultural, agora a caminho de uma utopia transmoderna. Trata-se de uma estratégia de crescimento e criatividade de uma cultura não só decolonizada, mas renovada.

O diálogo, então, entre os críticos criadores de suas próprias culturas já não é moderno nem pós-moderno, mas estritamente "transmoderno", porque, como mencionado acima, a localização do esforço criador não parte do interior da modernidade, mas de sua externalidade, ou melhor, de seu ser "fronteiriço". A exterioridade não é pura negatividade. É uma positividade de uma tradição distinta da tradição moderna. Sua afirmação é novidade, desafio e inclusão do melhor da própria modernidade. Por exemplo, nas culturas indígenas da América Latina, há uma afirmação de uma natureza completamente distinta e mais equilibrada, ecológica e, hoje, mais necessária do que nunca, em relação à forma como a Modernidade capitalista confronta a natureza como simplesmente explorável, negociável e destrutível. A morte da natureza é o suicídio coletivo da humanidade, no entanto, a cultura moderna que se globaliza nada aprende a respeito da natureza com outras culturas, aparentemente mais "primitivas" ou "atrasadas", de acordo com os parâmetros vigentes de desenvolvimento. Este princípio ecológico pode integrar o melhor da Modernidade (não se deve negar toda a Modernidade a partir de uma identidade substantiva purista de sua própria cultura) para construir até mesmo o desenvolvimento da ciência e da tecnologia a partir de experiências da própria Modernidade.

A afirmação e o desenvolvimento da alteridade cultural dos povos pós-coloniais, integrando-se ao melhor da Modernidade, não deve se desenvolver em um estilo cultural que leve a uma unidade globalizada, indiferenciada ou vazia, mas a um pluriverso transmoderno (com muitas universalidades: europeia, islâmica, vedanta, taoista, budista, latino-americana, bantu etc.), multicultural, em um diálogo crítico intercultural.

Abstract: This article recognizes a new location of so called peripheral cultures in world history, and subscribes to a non-monolithic and non-substantialistic concept of culture. It locates Europe's specificity in world history and proposes a symmetrical intercultural dialogue between critics from "peripheral" cultures. These cultures have been colonized, excluded, despised, denied and ignored by eurocentered modernity, but have not been eliminated. The challenge ahead is to establish a transmodern and symmetrical dialogue between these cultures - treated as exteriorities of modernity - in order to deal the challenges set forth by European modernity and postmodernity from a different location.

Keywords: transmodernity, interculturality, philosophy of liberation, exteriority, world-system. 


\section{Referências}

AL-YABRI, Mohamed. Crítica de la razón árabe. Barcelona: Icaria, 2001a.

- El legado filosófico árabe: Alfarabi, Avicena, Avempace, Averroes, Abenjaldún. Lecturas contemporâneas. Madrid: Trotta, 2001b.

ARCE, Bayardo. El deficil terreno de la lucha: el ideológico. Nicaráuac, v. 1, p.155$163,1980$.

ARDILES, Osvaldo. Ethos, cultura y liberación. In: CAMBEIRO, Fernando Garcia (Org.). Cultura popular y filosofia de la liberación. Buenos Aires: Americalee, 1975.

BAGÚ, Sergio. Economía de la sociedade colonial: ensayo de história comparada de América Latina. Buenos Aires: Libreria El Ateneo Editorial, 1949.

BONDY, Salazar. Existe una filosofia en nuestra América? Mexico: Siglo XXI, 1969.

BOSI, Ecléa. Cultura de massa e cultura popular. Petrópolis: Vozes, 1977.

CABRAL, Amílcar. Cultura y liberación nacional. Ciudad de Mexico: Cuicuilco, 1981.

CARDENAL, Ernesto. Cultura revolucionária, popular, nacional, anti-imperialista. Nicaráuac, v. 1, p. 163-179, 1980.

DUSSEL, Enrique. Para una ética de la liberación latinoamericana - v. I-II. Buenos Aires: Siglo Veintiuno Editores, 1973.

_. Para una ética de la liberación latinoamericana - v. III. Ciudad de Mexico: Edicol, 1977.

—. La pedagogia latinoamericana. Bogotá: Nueva America, 1980.

—. Historia general de la Iglesia en América Latina. Salamanca: Sígueme, 1983.

__. La producción teórica de Marx. Ciudad de Mexico: Siglo XXI, 1985.

- Oito ensaios sobre cultura latino-americana e libertação. São Paulo: Paulinas, 1997.

—. Hacia un Marx desconhecido. Ciudad de Mexico: Siglo XXI, 1988.

—. El último Marx. Ciudad de Mexico: Siglo XXI, 1990.

— Historia de la filosofia y filosofia de la liberación. Bogotá: Nueva América, 1994. 
- The invention of the Americas: eclipse of "the other" and the myth of modernity. New York: Continuum Publishing, 1995.

- Europe, modernity, and eurocentrism. Nepantla Views from South (Durham), v. I, isuee 3, p. 465-478, 2000.

-World-System and transmodernity. Nepantla Views from South (Durham), v. 3, isuee 2, p. 221-244, 2002.

- Towards an unknown Marx: a commentary on the manuscripts of 18611863. London: Routledge, 2001.

—. Materiales para una filosofia de la liberacción. Madrid: Plaza e Valdés editores, 2007.

FRANK, Andre. Gunder. ReOrient: global economy in the Asian age. Berkeley: University of California Press, 1998.

FSLN. La cultura del Pueblo. In: Habla la dirección de la vanguarda. Manágua: Departamento de Propaganda del FSLN, 1981.

GRAMSCI, Antonio. Quaderni del carcere I. Milan: Einaudi, 1975.

HARDT, Michel; NEGRI, Antonio. Imperio. Barcelona: Editorial Paidos, 2005.

HUNTINGTON, Samuel. The clash of civilization and the remaking of world order. New York: Simon \& Schuster, 1996.

LEVINAS, Emmanuel. Totalidade e infinito. Lisboa: Edições 70, 1988.

MENCHÚ, Rigoberta. Me llamo, Rigoberta Menchú y así nasció la conciencia. Ciudad de Mexico: Siglo XXI, 1995.

NAJENSON, José L. Cultura popular y cultura subalterna. Toluca: Editora Unam, 1979. POMERANZ, Kenneth. The great divergence: China, Europe and the making of the modern world economy. Princeton: Princeton University Press, 2000.

RAMIREZ, Sergio. La revolución, el hecho cultural más grande de nuestra história. Ventana, v. 30, Managua, 1982.

SAID, Edward. Orientalismo: o Oriente como invenção do Ocidente. São Paulo: Companhia das Letras, 2007.

SANTOS, Theotonio dos. La teoría de la dependencia: balance y perspectivas. Ciudad de Mexico: Plaza y Janés, 2002. 
SARMIENTO, Domingos Faustino. Facundo, ou civilização e barbárie. São Paulo: Cosac Naify, 2010.

SARTRE, Jean Paul. Prefácio. In: FANON, Frantz. Os condenados da Terra. Rio de Janeiro: Civilização Brasileira, 1968.

VIDALES, Raúl. Filosofía y política de las étnias en la última década. In: Ponencias do I/ Congreso de Filosofia Latinoamericana, USTA, p. 385-401, Bogotá, 1982.

WALLERSTEIN, Imannuel. The modern world-system I: capitalist agriculture and the origins of the european world-economy in the sixteenth century. New York: Academic Press, 1974.

- The modern world-system II: mercantilism and the consolidation of the european world-economy, 1600-1750. New York: Academic Press, 1980.

The modern world-system III: the second Era of great expansion of the capitalist world-economy, 1730s-1840s. New York: Academic Press, 1989.

WARMAN, Arturo. Cultura popular y Cultura Nacional. In: ZEA, Leopoldo (Org.). Características de la cultura nacional. Ciudad de Mexico: Unam, 1969. 